\title{
Research on Testing Method of the Wheel Loader Bucket Force
}

\author{
Zhengwen Yuan ${ }^{1,2, a}$, Hongfeng $\mathrm{Ma}^{1,2, \mathrm{~b}}$, Lei Xu ${ }^{1,2, \mathrm{c}}$, Shumin $\mathrm{Zhu^{1,2,d }}$ \\ ${ }^{1}$ Jiangsu Xuzhou Construction Machinery Research Institute, Xuzhou, 221004, China \\ ${ }^{2}$ State Key Laboratory of Intelligent Manufacturing of Advanced Construction Machinery, Xuzhou \\ Construction Machinery Group, Xuzhou, 221004, China \\ arunzhengwen@163.com, bmhfxyq@163.com, c380778350@qq.com, d1536965298@qq.com
}

Keywords: Wheel loader; Bucket Force; Strain bridge

\begin{abstract}
The wheel loader is under lots of complex conditions, suffered heavy load, and the $t$ fatigue damage often occurred on the work device. Due to the complexity of the digging process, the load of the wheel loader is hard to be tested. As the result, the load for designing structure of the work device is mostly static load, which is far from the actual load. In this paper, a method for testing the external load of the bucket is proposed. The external load can be tested by the simple strain bridge. The experimental results show that the error is within $5 \%$ and the angle deviation is within $4^{\circ}$.
\end{abstract}

\section{Introduction}

Wheel loader is a kind of earthwork machinery as shown as Fig. 1, which can be used in construction, harbor, mine, railway, mining and so on. It can carry out excavation work on soil and stone side, and carry out material handling operation for truck and other transportation vehicles. When the loader carries out the shoveling operation, the arm cylinder can be stretched and compressed in order to transmit the force to the rod through the rocker arm. The drawbar can drive the bucket to swing around the hinge point of the boom. The boom cylinder can make the whole working device rotate around the front frame. So the materials can be upgraded. When the loader is working, the load characteristics of the bucket are very significant for the design of the loader. Many scholars have done related research on the load of the loader[1-6]. However, the load was obtained by the theoretical calculation or simulation in the above research, which is quite different from the real situation. In this paper, a loader bucket force test method is proposed. Based on this method, the load of the wheel loader can be tested in actual shoveling process with 5 strain bridges.

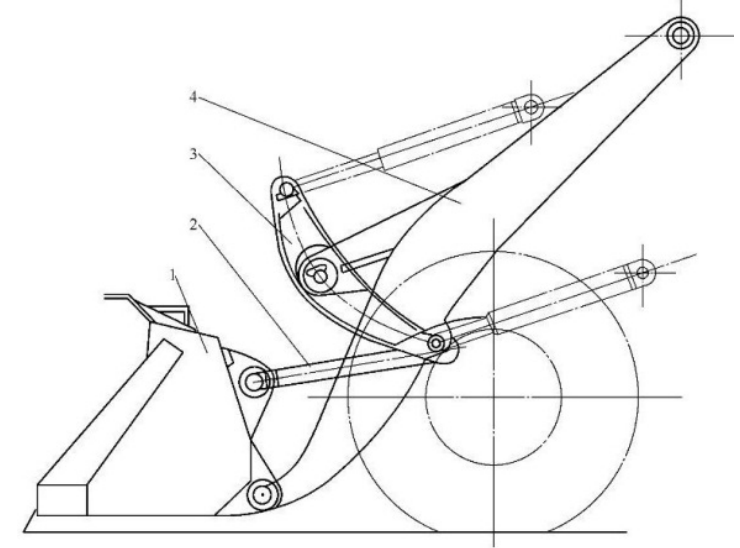

1 - bucket; 2 -drawbar; 3 - swing arm; 4 - boom

Figure1.Structure of the loader working device 


\section{Model establishing}

\subsection{Calculation of the connecting rod force}

As shown in Figure 1, the loader working device mainly includes the following four components: 1 for the bucket, 2 for the boom, 3 for the connecting rod, 4 for the rocker. When the loader is working, the force $F$ of the bucket 1 is balanced with the force $\mathbf{F}_{\mathbf{E}}$ and force $\mathbf{F}_{\mathbf{C}}$. If $\mathbf{F}_{\mathbf{E}}$ and $\mathbf{F}_{\mathbf{C}}$ are measured, the force of the bucket 1 in the plane shown in Fig. 1 could be calculated. The connecting rod 3 is a two-force bar, which the force sensor can be easily to set on.

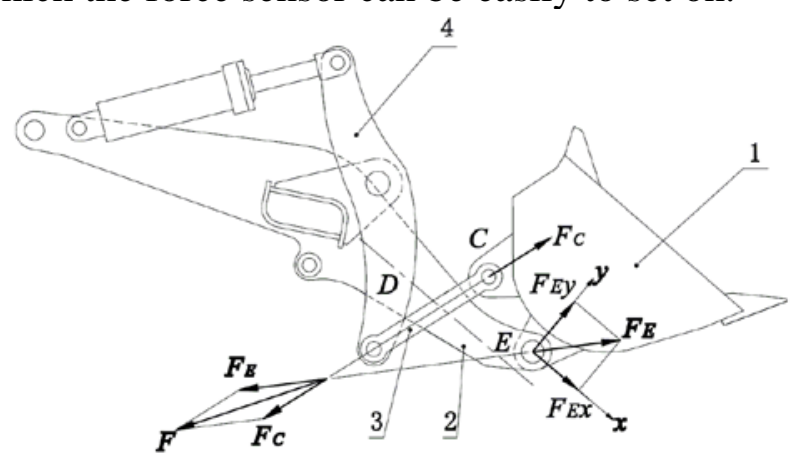

Figure2.Working device force diagram

\subsection{Calculation of the force between the boom and the bucket.}

As shown in Fig. 2, at the first, the angle bisector A of the upper and lower surfaces of the boom 2 is draw; at the second, the cross-section A and B of the boom are draw, which are required to be perpendicular to $\mathrm{D}$, at the last, set the $\mathrm{E}$ as the origin of the coordinates, set the direction which parallels to the bisector D (as shown as Fig. 2 and Fig. 3) as the x-axis of the coordinates, set the direction which is perpendicular to the $\mathrm{x}$-axis as $\mathrm{y}$-axis.

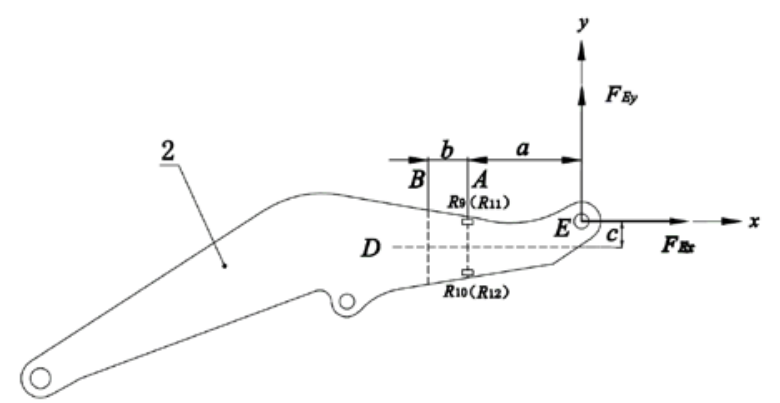

Figure3.Cross-section A and B diagram

As shown in Figs. 2 and 3, the radial force of the hinge pin at $\mathrm{E}$ on the boom 2 is divided into the component force $\mathbf{F}_{\mathbf{E x}}$ in the $\mathrm{x}$ direction and the component force $\mathbf{F}_{\mathbf{E y}}$ in the y direction. It can be seen that $\mathbf{F}_{\mathbf{E x}}$ is parallel to $\mathrm{D}$ and their distance is $\mathbf{C}, \mathbf{F}_{\mathbf{E y}}$ is perpendicular to $\mathrm{D}$, the distance from cross section A to $\mathbf{F}_{\mathbf{E y}}$ is a , and the distance between cross section A and B is b.

Set the bending moment on section $\mathrm{A}$ as $\mathbf{M}_{\mathbf{A}}, \mathrm{B}$ as $\mathbf{M}_{\mathbf{B}}$, and the following equations by the torque balance equation can be obtained.

$$
\begin{aligned}
& F_{E x}=\frac{M_{B}-M_{A} a-M_{A} b}{b c} \\
& F_{E y}=\frac{M_{B}-M_{A}}{b}
\end{aligned}
$$

In equ.1 and 2, a, b and c are design parameters. $\mathbf{M}_{\mathbf{A}}$ and $\mathbf{M}_{\mathbf{B}}$ can be measured by strain bridges as shown as Fig. 4. 


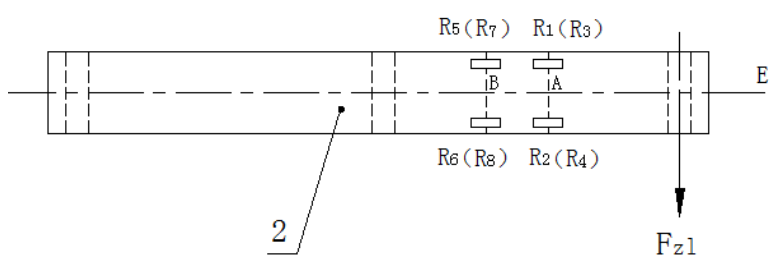

Figure4. strain bridges of A and B

The bridge circuits on A and B are shown in Fig. 4.

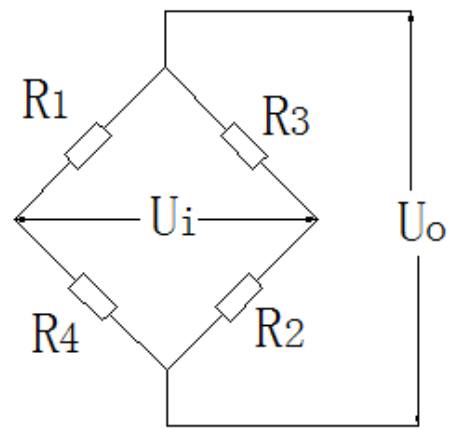

a)

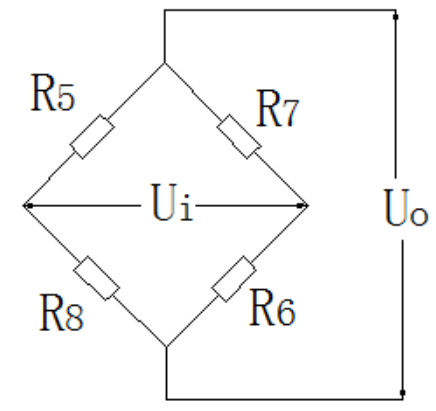

b)

Figure5. Bridge circuits on A and B

The output signal of the bridge is proportional to the bending moment $\mathbf{M}_{\mathbf{A}}$ and $\mathbf{M}_{\mathbf{B}}$ on the cross section $\mathrm{A}$ and $\mathrm{B}$.

\subsection{Calculation of lateral force FZ.}

In addition to the force $\mathbf{F}_{\mathbf{E x}}$ and force $\mathbf{F}_{\mathbf{E y}}$ shown in Fig. 2 there is a lateral force $\mathbf{F}_{\mathbf{z}}$. As shown in Fig. 4, $\mathbf{F}_{\mathbf{z}}$ is perpendicular to $\mathbf{F}_{\mathbf{E x}}$ and $\mathbf{F}_{\mathbf{E y}}$.

As shown in Fig. 3, the strain gages R9, R10 are attached to the cross-sectional surface A at the position of intersection with the side surface of the boom 2, and R9 and R10 are symmetrical about the Line $\mathrm{D}$, The direction of the strain gage sticking is parallel to the direction of the line $\mathrm{D}$. The strain gages R11 R12 are attached to the cross-sectional surface A at the position of intersection with the other side surface of the boom 2, and R11 and R12 are also symmetrical about the Line D, The direction of the strain gage sticking is parallel to the direction of the line D.

The strain gauge R9, R10, R11, R12 group a bridge shown in Fig. 6. The output signal of this bridge is proportional to the lateral force $\mathrm{Fz}$ at the origin $\mathbf{E}$ of the boom 2 .

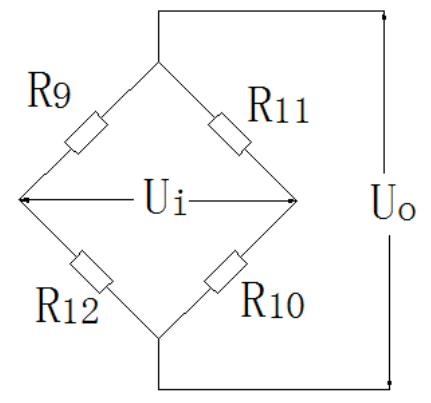

Figure 6. Bridge circuits for $\mathrm{Fz}$

In fact, the loader has about two booms, in the actual test, the two booms should be measured at the same time. If the test values of the left boom are $\mathbf{F}_{\mathbf{E x l}} 、 \mathbf{F}_{\mathbf{E y l}} 、 \mathbf{F}_{\mathbf{z l} \text {, and }}$ the test values of the right boom are $\mathbf{F}_{\mathbf{E x}} 、 \mathbf{F}_{\mathbf{E y}}$ and $\mathbf{F}_{\mathbf{z}}$. the $\mathbf{F}_{\mathbf{E x}} 、 \mathbf{F}_{\mathbf{E y}}$ 和 $\mathbf{F}_{\mathbf{z}}$ could be obtained by eqns. (3-5).

$$
\begin{gathered}
\boldsymbol{F}_{E x}=\boldsymbol{F}_{E x l}+\boldsymbol{F}_{E x r} \\
F_{E y}=F_{E y l}+F_{E y r} \\
F_{z}=F_{z l}+F_{z r}
\end{gathered}
$$




\section{Model validation}

In order to investigate the accuracy of the test model, the static loading test is used to verify the method. Due to $5 \mathrm{~T}$ loader shovel material weight is generally between $50 \mathrm{KN}$ to $70 \mathrm{KN}$, so choose the weight $5 t, 6 t, 7 t$ as the test load. Loader in the whole working process, the wheel loader has digging, transport, lift, discharge postures, so take above 4 postures as static load test as shown as Fig.7. The test site is shown as Fig. 8.

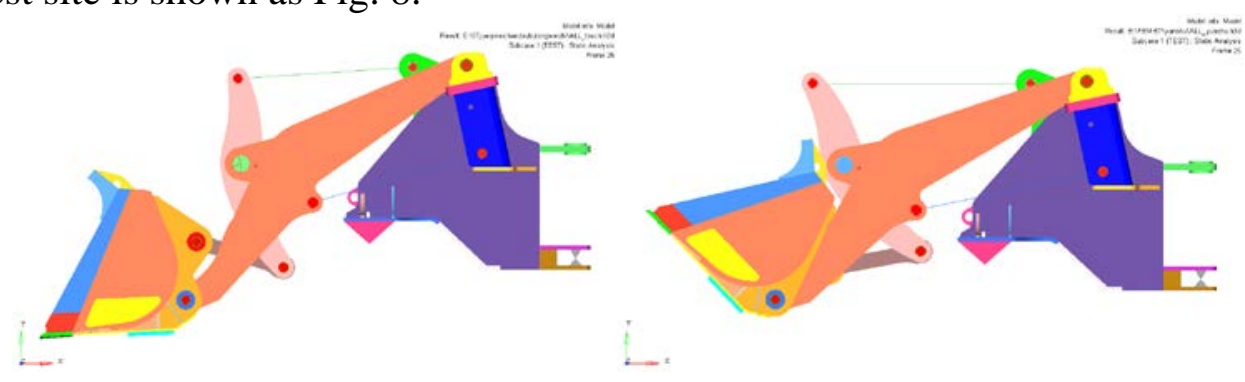

a)Position of the shoveling b)Position of the transport
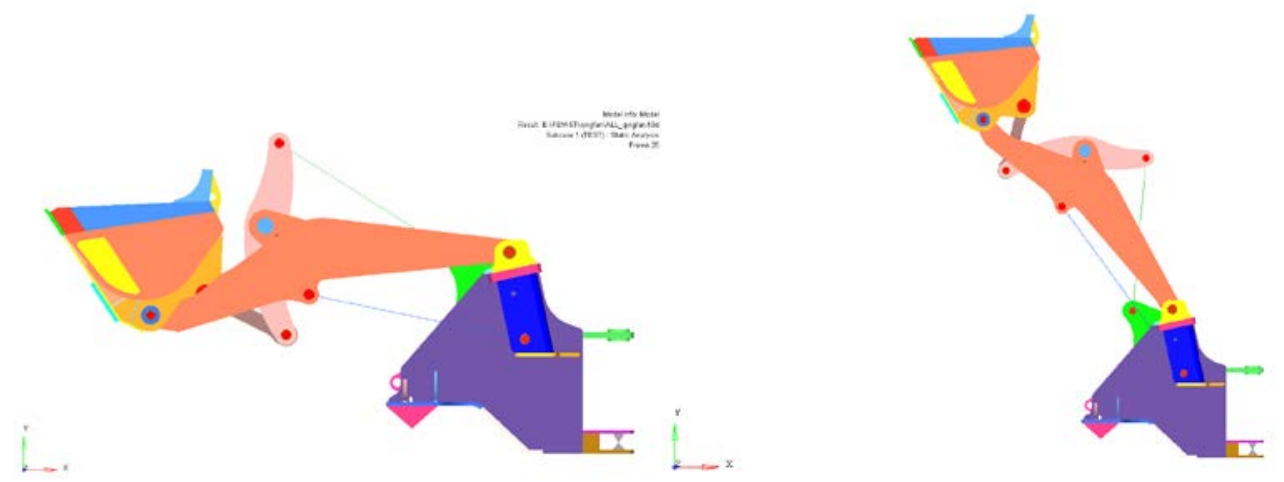

c) Position of the hold flat d) Position of the unload

Figure 7.Position of the test

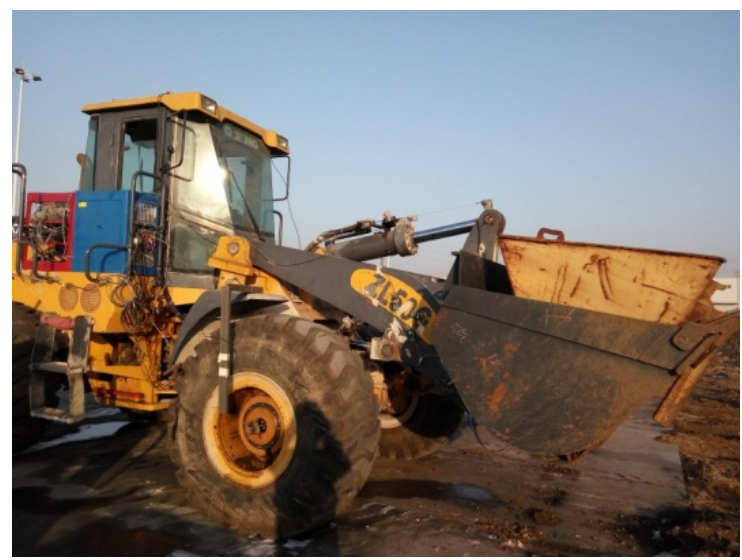

Figure 8.Static load verification test

The test procedure is as follows:

1) The bucket is idle and the rocker is controlled to rotate the bucket to pose 1 (shovel pose), lift the boom slowly, and keep the position unchanged when the boom is lifted to a point where the lower hinge point is $400 \mathrm{~mm}$ above the ground, and record the values of each sensor .

2) The bucket is loaded weight to the same step gesture with the step1, record the values of each sensor.

3) Change the loader position to position 2 (transport ), 3 (flat position), 4 (discharge position), and repeat steps 1 and 2 respectively.

4) Test the weight of loaded weight, test accuracy is $10 \mathrm{~kg}$.

5) Test the center of gravity by hanging method. 
The results are shown as Tab. I.

TABLE I. TEST RESULTS

\begin{tabular}{ccccc}
\hline Postures & $\begin{array}{c}\text { Test } \\
\text { load } \\
{[\mathrm{kN}]}\end{array}$ & $\begin{array}{c}\text { Calculate } \\
\text { load } \\
{[\mathrm{kN}]}\end{array}$ & $\begin{array}{c}\text { Error } \\
{[\%]}\end{array}$ & $\begin{array}{c}\text { Angle } \\
\text { deviation }\left[{ }^{\circ}\right]\end{array}$ \\
\hline Posture 1 & 49.2 & 51.32 & 4.31 & 3.12 \\
& 59.78 & 62.11 & 3.90 & 2.47 \\
Posture 2 & 68.79 & 70.1 & 1.90 & 0.58 \\
& 49.2 & 49.5 & 0.61 & 1.67 \\
& 59.78 & 60.32 & 0.90 & 2.41 \\
Posture 3 & 68.79 & 69.48 & 1.00 & 1.54 \\
& 49.2 & 50.51 & 2.66 & 3.24 \\
& 59.78 & 60.27 & 0.82 & 0.57 \\
Posture 4 & 68.79 & 70.87 & 3.02 & 3.27 \\
& 49.2 & 50.31 & 2.26 & 1.67 \\
& 59.78 & 61.23 & 2.43 & 4.65 \\
& 68.79 & 71.65 & 4.16 & 1.29 \\
\hline
\end{tabular}

According to Tab.I, It can be seen that the calculate results are closed to test result in different bucket posture and external load. The value error is within $5 \%$ and the angle deviation is within $4^{\circ}$.

\section{Conclusion}

1) According to the structural characteristics of the loader working device, the force balance analysis is carried out to obtain the torque balance equation of the boom in $\mathrm{x}, \mathrm{y}$ and $\mathrm{z}$ directions, based on which, a bucket load test system is established with strain bridges.

2) A static load validation experiment under typical postures is designed, and the results are shown that the value error of the new model is within $5 \%$ and the angle deviation is within $4^{\circ}$.

\section{Acknowledgment}

This work has been supported by National Key Technology Support Program, Number 2015BAF07B02. The corresponding author is Zhengwen Yuan.

\section{Reference}

[1] W.Q. Shen, A.Y. Hao, Z.H. Zhu, et al. Optimization design of loader connecting rod mechanism based on MATLAB[J]. Coal Mine Machinery, 2006, vol.27, pp. 544-546.

[2] G.L. Meng, the consideration of the load for the working mechanism of loader[J]. Construction Machinery, 1999, pp. 64-66.

[3] S.X. Pan, H.B. Liu , P.N. Feng. Optimization design of 8-bar linkage working mechanism of wheel loaders[J]. Journal of Tongji University, 2001, vol. 29, pp. 1499-1502.

[4] X.H. Gao, Y.C. Wang, E.Z. An, et al. Optimization of the working device of loader based on ADAMS[J] . Computer Simulation, 2007, vol. 24, pp. 217-221.

[5] K. Shi, S. Lee, et al. Couple linkage system optimization for minimum power consumption[J]. Journal of Mechanical Science and Technology, 2012, vol. 26, pp.1099-1106.

[6] X.M. Wang, J.J. Zhang, H.B. Song. Loader Attachment Simulation and Optimal Design Based on ADAMS[J], Construction Machinery and Equipment, 2014, pp. 128-135. 